\title{
Calcium distribution and function in the glandular trichomes of Lavandula pinnata $\mathbf{L}$.
}

\author{
Shan-Shan Huang ${ }^{1,2}$ \\ The Institute of Chinese Medicine of Guangdong Province, Guangzhou, 510520, China \\ Jing-Ping Liao \\ South China Botanical Garden, Chinese Academy of Sciences, Guangzhou, 510650, China \\ Bruce K. Kirchoff \\ University of North Carolina at Greensboro, Department of Biology, Greensboro, NC 27402
}

\begin{abstract}
Huang, S-S. (The Institute of Chinese Medicine of Guangdong province, Guangzhou, 510520, China), J.-P. Liao (South China Botanical Garden, Chinese Academy of Sciences, Guangzhou, 510650, China). AND B. K. Kirchoff (University of North Carolina at Greensboro, Department of Biology, Greensboro, NC 27402), Calcium distribution and function in the glandular trichomes of Lavandula pinnata L. J. Torrey Bot. Soc. 137: 1-15. 2010.-Calcium distribution during peltate and capitate glandular trichome development in Lavandula pinnata L. was examined with the potassium antimonate precipitation method. In order to establish a role for calcium in the secretory process and elucidate calcium function in the glands, the effects of calcium removal were investigated by treatment with nifedipine (Nif, a calcium channel blocker) and Ethylene glycol-bis (2-aminoethyl ether)-N, N, N', N'-tetraacetic acid (EGTA, a calcium chelator). Untreated, mature glands accumulate many calcium precipitates in the subcuticular space and adjacent cell wall during secretion. In Nif or EGTA treated plants these precipitates disappear, and the amount of secretory product is drastically reduced. Calcium removal also results in a reduction in gland density, cells with decreased cytoplasmic density, formation of a lax cell wall, abnormal formation of the subcuticular space, thinning of the cuticle, and the presence of multivesicular bodies near the plasma membrane. At the post-secretory stage, calcium precipitates are common on the degenerating organelles. These results support a role for calcium in gland development, secretion, and programmed cell death.
\end{abstract}

Key words: antimonate precipitation, calcium, EGTA, glandular trichome, Lavandula pinnata L., nifedipine, secretion, ultrastructure.

Calcium is an essential element in biological systems. In its ionic form $\left(\mathrm{Ca}^{2+}\right)$ it has been shown to be crucial in the control of numerous physiological and developmental processes in plants (Bush 1995, Zhang and Cass 1997, Trewavas and Malhó 1998, Sanders et al. 1999, Scrase-Field and Knight 2003, Medvedev 2005, Wheeler and Brownlee 2008). For instance, the $\mathrm{Ca}^{2+}$ ion is involved in intracellular events such as protoplasmic streaming, nuclear division, cell division, cell plate formation, and polarized growth in rhizoids and pollen tubes (Takagi and Nagai 1983, SakaiWada and Yagi 1993, Malhó and Trewavas

${ }^{1}$ We thank the National Natural Science Foundation of China (39870087, 30370099, 40332021), and the Key Scientific Item of Guangdong (045C013) for financial support. Xing-Lan Xu and Xiao-Ying $\mathrm{Hu}$, instructors in the Electron Microscopy facility of the South China Botanical Garden, assisted the first author in learning EM.

2 Author for correspondence. E-mail: hss@scib. ac.cn

Received for publication August 6, 2009, and in revised form January 7, 2010.
1996, Taylor and Hepler 1997, Franklin-Tong 1999, Eckardt 2001, Plieth 2001, Campanoni and Blatt 2007). Removal of calcium from the nutrient supply results in rapid death of cells in the apical meristem, and a cessation of growth (Epstein 1972, Gilroy et al. 1993).

Pollen tubes have been found to respond to calcium gradients by elongating toward higher $\mathrm{Ca}^{2+}$ concentrations in in-vitro assays (Mascarenhas and Leonarad 1962, Pierson et al. 1994). When calcium channel blockers are added to the medium, pollen tube growth is restrained, suggesting that calcium is acting as an intercellular signal (Picton and Steer 1985, Pierson et al. 1994, Herrmann and Felle 1995, Fan et al. 1996, Carol et al. 1997). Consistent with this view, elevated cytosolic $\mathrm{Ca}^{2+}$ concentrations $\left(\left[\mathrm{Ca}^{2+}\right]_{\mathrm{c}}\right)$ have been reported to drive docking and fusion of exocytotic vesicles at the tip of pollen tubes (Carol et al. 1997). In a related study, Roy et al. (1999) found positive feedback between $\mathrm{Ca}^{2+}$ concentration and exocytosis in lily pollen tubes. According to this work, high concentrations of calcium promote exocytosis, thus providing more cell 
wall substance and causing the circumference of the cell membrane to increase, which in turn causes more calcium channels to open (Roy et al. 1999).

Calcium levels in the anther have also been studied and have been found to change with the stage of development. For instance, when visualized with potassium antimonate precipitation in photoperiod-sensitive male sterile rice, calcium precipitates accumulate in the anther walls, on the surface of pollen grains, and in Ubish bodies, but they are less frequent on the pollen surface at the late microspore stage (Tian et al. 1998). Later, as starch accumulates in the mature pollen grains, the number of calcium precipitates decreases in these cells and increases in the parenchymatous cells of the connective tissue (Tian et al. 1998). Changes in calcium distribution during development have also been reported in developing ovules of Nicotiana tabacum (Tian and Russell 1997), pollen grains of Chlorophytum elatum (Górska-Brylass et al. 1997), Torenia fournieri (Chen et al. 2008), and during pollen tube growth of tobacco (Xie et al. 2005a).

Calcium has also been implicated in the function of the stylar transmitting tract (Zhao et al. 2004), dividing root cells (Vaughan et al. 1987, Sakai-Wada and Yagi 1993) and potentially as a causative factor in Blossom-end rot of tomato (Suzuki et al. 2003). Despite what is known from these studies, a role for calcium in the secretion of essential oils has not been established.

The glandular trichomes of the Lamiaceae are a well-established source of essential oils. Two types of trichomes occur in the family. These trichomes are termed peltate or capitate depending on the structure of the secretory head (Werker 1993). In both cases, the secretory product accumulates in a subcuticular space outside of the cell wall. The peltate trichomes produce most of the essential oil, with terpenes comprising the main component (Clark et al. 1997, Turner et al. 2000). The capitate trichomes secrete varying amounts of polysaccharides in addition to some terpenes (Werker 1993). Prior to secretion, the trichomes undergo several cell divisions, and the cuticle thickens. The subcuticular space forms between the cuticle and the cell wall, and enlarges as the essential oil is secreted (Ascensão et al. 1997, Turner et al. 2000, Gersbach 2002, Huang et al. 2008).
As in other Lamiaceae, Lavandula pinnata possesses two kinds of glandular trichomes (Ascensão and Pais 1998, Gersbach 2002, Huang et al. 2008). Both capitate and peltate trichomes are initiated from a single protodermal cell, and undergo several cell divisions to produce stalk and head cells. However, while there are one to two secretory cells in the head of a capitate trichome, there are eight cells in the head of a peltate trichome (Huang et al. 2005, 2008). In both cases, gland development is very rapid (approximately $60 \mathrm{~h}$ ) in comparison to leaf expansion (1825 d, Huang et al. 2008). Three different secretory stages can be recognized: presecretory, secretory and post-secretory (Ascensão and Pais 1998, Turner et al. 2000, Huang et al. 2005, 2008). The mechanism of secretion is similar to that of other Lamiaceae (Huang et al. 2008).

In this study, potassium antimonite precipitation is used to investigate loosely bound calcium distribution during both capitate and peltate glandular trichome development. The calcium channel blocker nifedipine (Nif) and the calcium chelator Ethylene glycol-bis (2aminoethyl ether)-N, N, N', N'-tetraacetic acid (EGTA) are used to elucidate calcium function during gland development (Williams 1970, Reiss and Herth 1985, Rosales and Brown 1992, Fan et al. 1996, Moysset and Simón 1990, Zhang et al. 2000). Using these calcium antagonists, we investigate the effects of calcium on trichome number, morphology, development, and on the secretory process itself.

Material and Methods. Micropropagation of Apical Shoots. Plants of Lavandula pinnata L. were grown in a greenhouse at the South China Botanical Garden, Guangzhou, China. Apical shoot explants for the study of calcium distribution were prepared according to the procedure of Huang et al. (2008). Trichome development was studied under four growth conditions: light-grown control, dark-grown control, $100 \mu \mathrm{M}$ Nif (maintained in the dark), and $5 \mathrm{mM}$ EGTA (maintained in the light). The dark-grown control was necessary because Nif is inactivated by light, so Nif treated plants must be maintained in the dark (Dentinger 2003).

Calcium Visualization. Calcium is present in plant tissues in free (ionic), loosely bound, 
and bound states. Visualization of each pool is strongly technique dependent (Ge et al. 2007). Although a precise microspectrofluorometric method is available to measure free cytosolic calcium $\left(\left[\mathrm{Ca}^{2+}\right]_{\mathrm{c}}\right)$ (Pierson et al. 1994), it is not possible to use this method for the study of glandular trichomes because of the difficulty in penetrating the cell wall by microinjection. In this study we used potassium antimonite to label loosely bound calcium, which can be readily converted to free calcium upon the appropriate environmental signal, such as $\mathrm{pH}$ (Tian et al. 1998, Ge et al. 2007). Potassium antimonate precipitation is a sensitive transmission electron microscopy (TEM) method long known to label loosely bound calcium (Wick and Hepler 1982, Slocum and Roux 1982, Jian et al. 1999). Both calcium localization and the effects of Nif and EGTA were investigated in capitate and peltate trichomes, but precipitate counts are only reported for peltate trichomes. Detailed counts of calcium precipitates were not carried out for the capitate trichomes. Inspection of the TEMs showing calcium localization in these trichomes showed the same results as for the peltate trichomes.

Administration of Nif to Seedlings. The effects of the calcium blocker nifedipine (Sigma, St. Louis, MO, U.S.A.) were evaluated in explants growing on Murashige and Skoog (1962) basal medium supplemented with $100 \mu \mathrm{M}$ Nif dissolved in DMSO at $10^{-2} \mathrm{M}$ as a preservative. DMSO concentrations $<10^{-1} \mathrm{M}$ were found to have no effect on glandular trichome development. The cultures were maintained at $25 \pm 2{ }^{\circ} \mathrm{C}$ in the dark to prevent inactivation of Nif (Dentinger 2003). Previous work has shown that the lack of illumination does not effect trichome development (Huang et al. 2008).

After evaluating the effects of different Nif concentrations $(1,10,100,250$, and $500 \mu \mathrm{M})$ on seedling growth, $100 \mu \mathrm{M}$ was selected as the key experimental concentration of Nif. Fan et al. (1996) used similar concentrations in their investigation of the effects of Nif on pollen germination, pollen tube growth, and the division of the generative nucleus in Nicotiana tabacum. When Nif concentration ([Nif]) was between 1 and $10 \mu \mathrm{M}$, L. pinnata seedlings grew indefinitely with little effect on gland development or ultrastructure. Fifteen days of treatment with a [Nif] of $100 \mu \mathrm{M}$ caused the leaf margins to dry, and some buds to stop growing. When [Nif] was increased to $250 \mu \mathrm{M}$, the leaves began to dry out after 10 days and the seedlings died after 15 days. At $500 \mu \mathrm{M}[\mathrm{Nif}]$ the seedlings died after just three days.

Administration of EGTA to Seedlings. The effects of EGTA were evaluated in seedlings that were transferred from micropropagation to potting soil and then to sand. Greenhouse grown seedlings approximately $5 \mathrm{~cm}$ in length, and about one month old, were transferred to small plastic cups containing sand and a complete fertilizer. The transferred seedlings were watered once a day for seven days with $5 \mathrm{mM}$ (pH 6.5) EGTA (Sigma, St. Louis, MO, U.S.A.) (Zhang et al. 2000). The cultures were maintained at $25 \pm$ $2{ }^{\circ} \mathrm{C}$ with $16 \mathrm{~h}$ day length at a light intensity of 10-20 $\mu \mathrm{mol} \mathrm{m}^{-2} \mathrm{~s}^{-1}$ using Philips TLD 36W/84 bulbs.

Transmission Electron Microscopy. After approximately $20 \mathrm{~d}$ of growth, 2-3 mm leaves were selected from micropropagated or greenhouse-grown buds from of all four treatments (light-grown control, dark-grown control, $100 \mu \mathrm{M}$ Nif, and $5 \mathrm{mM}$ EGTA). The leaves were cut into approximately $1 \mathrm{~mm}^{2}$ pieces and fixed in $2 \%$ glutaraldehyde in $0.1 \mathrm{M}$ potassium phosphate $\left(\mathrm{KH}_{2} \mathrm{PO}_{4}\right)$ buffer $(\mathrm{pH}$ 7.8) containing $1 \%$ potassium antimonate $\left(\mathrm{K}_{2} \mathrm{H}_{2} \mathrm{Sb}_{2} \mathrm{O}_{7} \cdot 4 \mathrm{H}_{2} \mathrm{O}\right)$. Fixation was carried out for $4 \mathrm{~h}$ at $4{ }^{\circ} \mathrm{C}$. The fixed pieces were washed in three changes of $1 \%$ potassium antimonate in $0.1 \mathrm{M}$ potassium phosphate buffer $(0.5 \mathrm{~h}$ each), and post-fixed in $1 \%$ osmium tetroxide $\left(\mathrm{OsO}_{4}\right)$ for $16 \mathrm{~h}$ at $4{ }^{\circ} \mathrm{C}$ in the same potassium antimonite/buffer combination (Tian and Russell 1997, Tian et al. 2000). The post-fixed tissues were washed in three changes of $0.1 \mathrm{M}$ potassium phosphate buffer without antimonite, dehydrated in a graded ethanol series, and embedded in Spurr's resin. Ultra-thin sections $(80 \mathrm{~nm})$ were cut using a LeicaUltracut S ultramicrotome, stained with uranyl acetate and observed with a JEM-1010 TEM at $90 \mathrm{KV}$ (Sajo et al. 2005).

Precipitates were confirmed as calcium antimonate with a JEOL 2000FX TEM at $40 \mathrm{kV}$ equipped with an IXRF energydispersive X-ray analysis system. Deconvoluted peak ratios reflected a 2:1 ratio of antimony to calcium (Tian and Russell 
1997). Two additional controls were also used: 1) potassium antimonate was sometimes omitted from the solutions during processing to verify that the precipitates were caused by the experimental treatment, and 2) the presence of calcium in the precipitates was confirmed by incubating selected grids, with treated sections attached, in a solution of $0.1 \mathrm{M}$ EGTA for $1 \mathrm{~h}$ at $37^{\circ} \mathrm{C}$. Removal of precipitates confirmed the presence of calcium (Tian and Russell 1997).

Cuticle thickness was determined from TEM micrographs. Ten images of six postsecretory peltate glandular trichomes from each of three specimens from the light-grown, dark-grown, and $100 \mu \mathrm{M}$ Nif treatments were measured. Cuticle thickness was also observed, but not measured, in six EGTA-treated trichomes.

The abundance of the calcium precipitates in peltate trichomes was determined by calculating the number of the precipitates per $\mu \mathrm{m}^{2}$ on each micrograph. Six peltate glandular trichomes were examined at each stage to determine calcium abundance (Table 1).

Scanning Electron Microscopy. Whole leaves $(1-5 \mathrm{~mm})$ were selected from all four treatments (light-grown control, dark-grown control, $100 \mu \mathrm{M}$ Nif, and $5 \mathrm{mM}$ EGTA) and fixed in $2 \%$ glutaraldehyde in $0.1 \mathrm{M}$ sodium phosphate buffer ( $\mathrm{pH} 7.2)$ for $4 \mathrm{~h}$ at $4^{\circ} \mathrm{C}$. After washing in the same buffer, the material was dehydrated in a graded ethanol series, transferred to amyl acetate and dried in an Emitech K850 critical point driver (Machado et al. 2006). Samples were mounted on stubs, coated with gold in a Polaron E5000 sputter coater (Eat-Stgrinftead, UK), and examined with a JSM-6360 scanning electron microscope at $15 \mathrm{kV}$.

Gland density was determined from SEM micrographs of abaxial surfaces of whole leaves. Care was taken to measure gland density at the same stages $(1,2,3$, and $4 \mathrm{~mm})$ in all treatments, as density varies at different stages. Three specimens from each treatment, and two leaves per specimen were analyzed. All of the glands on a leaf were counted.

Results. Confirmation of Precipitates as Calcium Antimonite. Omission of potassium antimonate from the processing solutions resulted in no precipitates, confirming the necessity of this chemical for their formation.
Treatment of normally processed sections with the calcium chelator EGTA resulted in the removal of the larger precipitates $(>100 \mathrm{~nm})$, although some smaller precipitates entirely enclosed in the embedding resin remained. Osmiophilic bodies were not affected by this treatment.

Changes in Calcium Distribution During the Early Presecretory Stages. It is not possible to distinguish between capitate and peltate glands at the early presecretory stages. The number of cells in the trichome increases from one to three during this stage. Calcium abundance is reported as an average of all cells in the trichome during this period (Table 1).

Calcium precipitates are common at the beginning of gland development when the gland initial begins to protrude above the epidermal cells. Deposits are abundant in the cell wall, common in the nucleus, and on the tonoplast and plasma membrane, and uncommon in the mitochondria, cytoplasmic matrix, and plastids (Table 1; Fig. 1A, black dots). At the two-celled stage, calcium precipitates decrease in the cell wall, and decrease slightly in the plastids, mitochondria and on the tonoplast, while remaining relatively constant elsewhere (Fig. 1B). At the three-celled stage, calcium precipitates decrease on the plasma membrane, and decrease slightly on the tonoplast and in the plastids (Fig. 1C). Though the frequency of precipitates is low on the plasma membrane and in the plastids, mitochondria, and cytoplasm at the tree-cell stage, the precipitates are larger than those observed at earlier stages (Fig. 1C).

Calcium Distribution During Peltate Glandular Trichome Development. Although we investigated both capitate and peltate trichomes, precipitate abundances were not determined for the capitate trichomes as TEM observation suggested that precipitate abundances were similar to those found in peltate trichomes. We report precipitate abundances only for peltate trichomes (Table 1).

At the presecretory stage, calcium distribution in the apical cells (AC) is similar to that at the early presecretory stage, except for on the plasma membrane where the number of precipitates increases significantly, and on the tonoplast where there are slightly more precipitates (Figs. 2A, B). Calcium precipitates are commonly observed on the cell walls, 


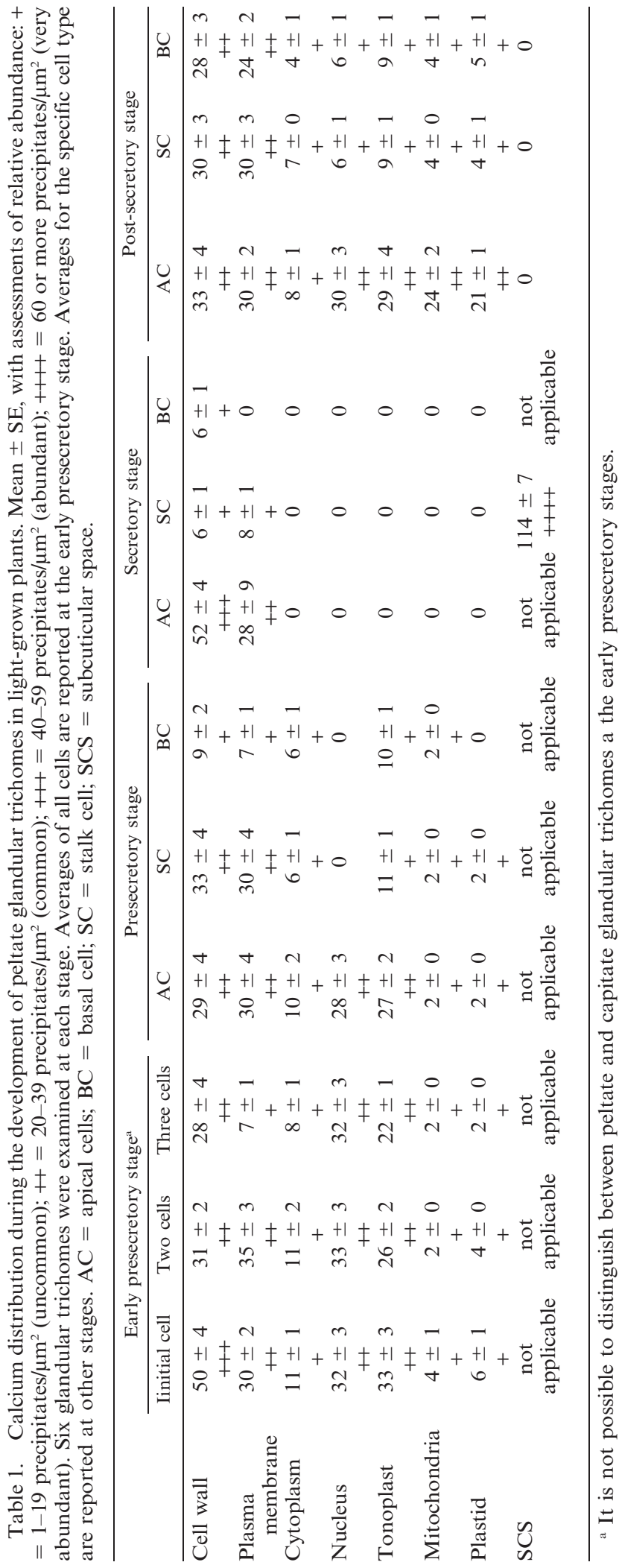



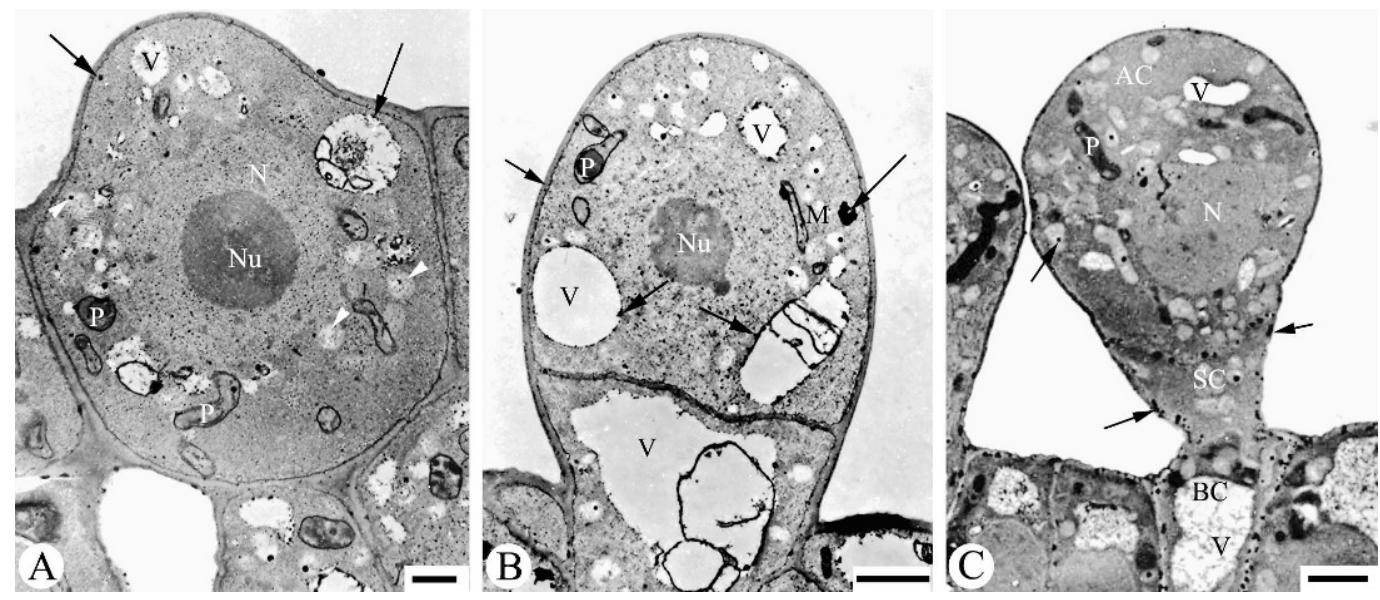

FIG. 1. TEM micrographs of light-grown (control) glandular trichomes during the early presecretory stages. It is not possible to distinguish between capitate and peltate glands at these stages. A. The initial cell of a glandular trichome. Calcium precipitates (dark spots, arrows) appear on the cell wall, plasma membrane, vacuole (V) membrane, and in the cytoplasm, nucleus, proplastids $(\mathrm{P})$ and mitochondria (white arrowheads). N: nucleus; Nu: nucleolus; scale $=1 \mu \mathrm{m}$. B. Two-celled stage of a glandular trichome with calcium precipitates (arrows). M: mitochondria; Nu: nucleolus; P: proplastids; V: vacuole; scale $=2 \mu \mathrm{m}$. C. Three-celled stage of a peltate glandular trichome with many large calcium precipitates (arrows) on the cell walls and in the organelles. N: nucleus; P: proplastids; V: vacuole; AC: apical cell; BC: basal cell; SC: stalk cell; scale $=5 \mu \mathrm{m}$

plasma membrane, tonoplast, and in the nucleus, and uncommonly in the cytoplasm, mitochondria and plastids (Table 1; Fig. 2B). Calcium distribution in the stalk cells (SC) show this same general pattern (Fig. 2C), except that precipitates are less frequently found in the cytoplasm and on the tonoplasts, and are absent from the nucleus. A few precipitates are found in, or adjacent to, the plasmodesmata that link the apical and stalk cells (Fig. 2D). There are fewer precipitates in the basal cell than in either the apical or stalk cells (Fig. 2C). These differences are especially apparent in the number of precipitates on the cell wall, and plasma membrane, and to a lesser extent in the plastids. As in the stalk cell, no precipitates occur in the nucleus of the basal cell. The numbers of precipitates in the cytoplasm, mitochondria and on the tonoplast are the same in the stalk and basal cells at the presecretory stage.

As secretion begins, the cuticle separates from the cell wall to form the subcuticular space (SCS), and many calcium precipitates appear in the SCS adjacent to the cell walls (Fig. 2E). As the SCS fills, more and more calcium precipitates appear in the SCS (Fig. 2F). During the secretory stage the number of precipitates increases in the cell wall of the apical cells, while decreasing in the cell walls of the stalk and basal cells. Precipitates remain common on the plasma membrane of the apical cells, while they decrease on the plasma membrane of the stalk cell, and disappear from all other regions of all three cells (Fig. 2G).

During the post-secretory stage, as the organelles begin to degenerate, calcium precipitates reappear in the cytoplasm and organelles of all cells, though they are most abundant in the apical cells (Fig. 2H). Calcium distributions in the stalk and basal cells are similar to each other, with higher concentrations in the cell wall and on the plasma membrane, and lower concentrations on the other organelles. Calcium precipitates are absent from the SCS at this stage (Fig. 2H).

Glandular Trichome Density Following Nif AND EGTA treatments. Nif and EGTAtreated plants show similar growth and ultrastructural defects in their trichomes. The effects become worse with increasing concentration of these chemicals. Symptoms include dry leaf margins, buds with tip burn, the cessation of apical growth, and decreased glandular trichome density.

There is little difference in trichome density between light and dark-grown seedlings (Fig. 3). However, gland density is reduced 
following treatment with Nif and EGTA. When [Nif] is between $1-10 \mu \mathrm{M}$ there appears to be little initial influence on trichome density. However, after the leaves enlarge trichome density of the Nif treated plants is less than the controls, suggesting a negative effect of Nif on cell division or enlargement of the trichome cells. With a [Nif] of $100 \mu \mathrm{M}$, gland density again decreases, and is less than half that of the controls at leaf maturity (Fig. 3). Treatment with EGTA also results in reduced trichome density. These results are consistent with the idea that Nif interferes with trichome development, but not with trichome initiation.

Changes in Ultrastructure and Calcium Distribution Following Treatment with NIF AND EGTA. Experiments with darkgrown control shoots (no Nif or EGTA) show no effect on calcium distribution in either type of trichome. For example, the precipitate count for the apical cell of light-grown secretory stage peltate trichomes is $52(\mathrm{SE}=$ $4, N=6$ ), while the same count for darkgrown peltate trichomes is $54(\mathrm{SE}=5, N=6)$ (Table 2).

The effects of Nif and EGTA treatment are similar in both types of trichomes. Following treatment, the cytoplasmic density of the cells decreases at all stages (Fig. 4A, B). At the early presecretory stage almost no calcium precipitates are observed in the gland initials (Fig. 4A). In a striking difference from untreated glands, parts of the cuticular layer separate from the cell wall at the presecretory stage to form an abnormal SCS (Fig. 4B, arrow). At the secretory stage, abnormal assemblages of vesicles are found adjacent to the plasma membrane, and may be in the process of fusing with it (Fig. 4C). Calcium precipitates are also almost completely absent from all of the cells at this stage, and from the SCS, which is nearly empty of secretory product (Fig. 4D). Large numbers of mitochondria also appear near the plasma membrane. Finally, at the post-secretory stage, a few calcium precipitates appear on the membranes of the degenerating plastids (Fig. 4E), the cell walls acquire a lax fibrillar appearance (Fig. 4E, arrows), and the cuticular layer is thinner than in the controls (Fig. 4F). The average cuticle thickness is $78 \mathrm{~nm}(\mathrm{SE}=8.45)$ following Nif treatment, and $97 \mathrm{~nm}(\mathrm{SE}=$ 10.36) following EGTA treatment, whereas its normal mean thickness is $200 \mathrm{~nm}(\mathrm{SE}=19.91)$ (Fig. 4F).

Discussion. The insoluble precipitates of calcium antimonate used in this study facilitate visualization of loosely bound calcium stores that may, under specific conditions, be mobilized and serve as a source of free calcium (Bush 1995, Tian et al. 2000). During the early stages of gland development, it is likely that the calcium so visualized is attached to membrane-bound binding sites, and is not free cytosolic calcium $\left(\left[\mathrm{Ca}^{2+}\right]_{c}\right)$. Calcium-binding proteins have been shown to be sensitive to environmental signals and developmental cues and, following the production of specific enzymes, may release free calcium in proportion to the local stores of loosely bound calcium (Weisenseel and Jaffe 1976, Tian et al. 2000). Electrically-gated $\mathrm{Ca}^{2+}$ channels, which have been described from the tonoplasts of several species, may further contribute to the release of free calcium (Allen and Sanders 1997, Tian et al. 2000). For these reasons, it is likely that the loosely bound calcium visualized with potassium antimonate can be readily converted into free calcium.

Bush (1995) reviewed the role of $\mathrm{Ca}^{2+}$ pumps in signaling processes. The pumps act to replenish intracellular calcium stores for channel-mediated $\mathrm{Ca}^{2+}$ release during signal transduction, supply $\mathrm{Ca}^{2+}$ for biochemical processes in organelles, maintain low $\left[\mathrm{Ca}^{2+}\right]$ in the cytoplasm, furnish $\mathrm{Ca}^{2+}$ for membrane interactions such as vesicle transport, membrane fusion, and secretion, and can account for spatiotemporal patterns of $\mathrm{Ca}^{2+}$ distribution.

Calcium Distribution During Glandular Trichome Development. Glandular trichome development in Lavandula pinnata is characterized by spatial and temporal changes in calcium levels throughout development. In the early stages of gland development many calcium-induced precipitates are found in the initial cells, especially on the cell walls, plasma membrane, tonoplast, and in the nucleus. At the presecretory stage, calcium tends to be concentrated in the apical cells, and on the cell wall and plasma membrane of the stalk cell. As the trichomes approach maturity and begin to secrete, calcium becomes very abundant in the SCS, abundant in the adjacent cell walls, and remains common on the plasma membrane. It is depleted elsewhere, and almost 

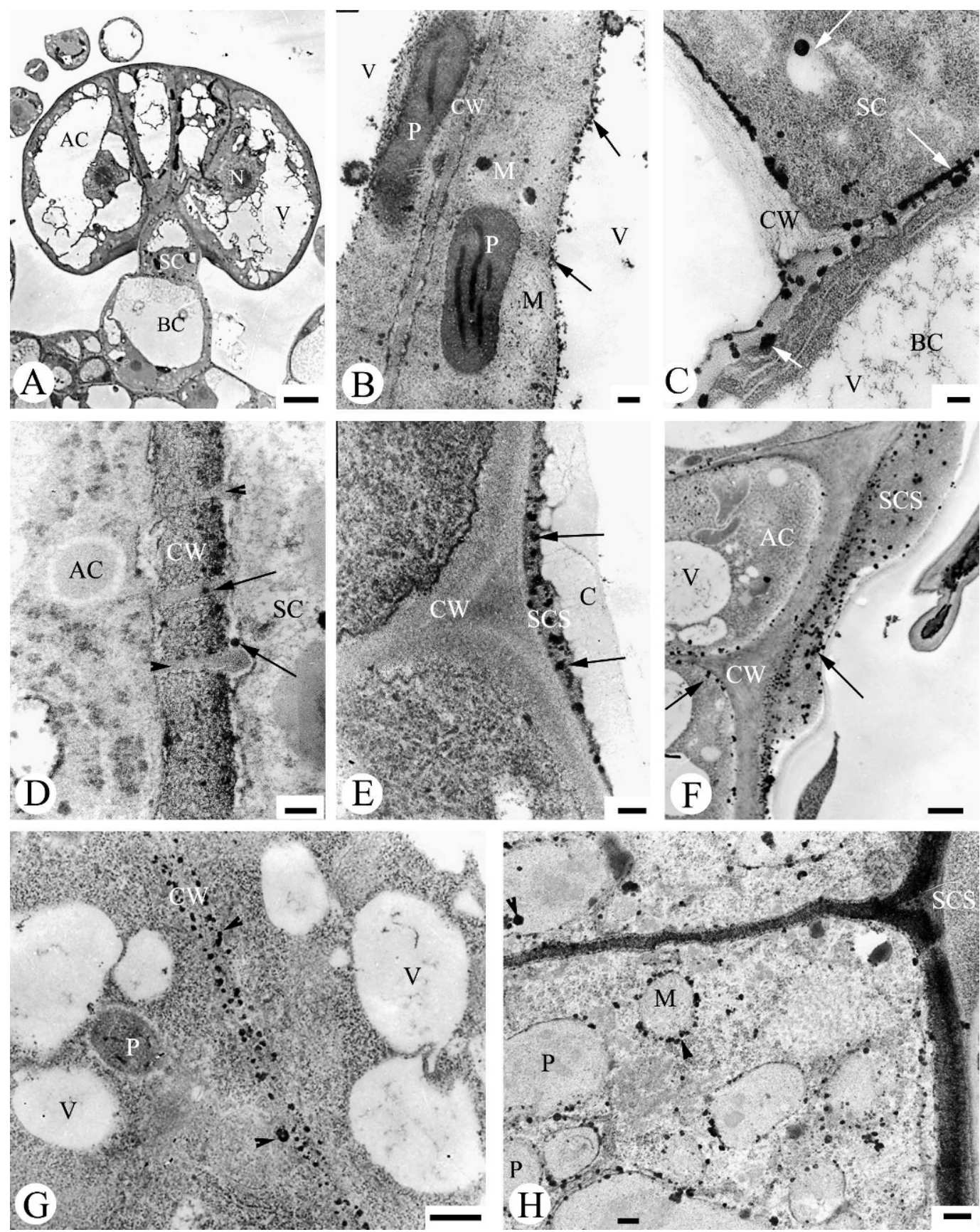

FIG. 2. TEM micrographs of light-grown (control) peltate glandular trichomes. A. Presecretory stage, showing calcium distribution (black dots) similar to the early presecretory stage. AC: apical cell; BC: basal cell; N: nucleus; SC: stalk cell; V: vacuole; scale $=2 \mu \mathrm{m}$. B. Enlarged image of the peripheral cytoplasm of two apical cells. Calcium precipitates (arrows) are located on the tonoplast, plasma membrane, plastid (P) membrane, and in the mitochondria (M). CW: cell wall; V: vacuole; scale $=200 \mathrm{~nm}$. C. Junction of the stalk (SC) and basal cells (BC) at the presecretory stage. Large calcium precipitates (white arrows) are located on the walls of the stalk and basal cells. CW: cell wall; V: vacuole; scale $=200 \mathrm{~nm}$. D. Calcium precipitates (arrows) in the plasmodesmata (arrowheads) between an apical disk cell (AC) and a stalk cell (SC), at the presecretory stage. CW: cell wall; scale $=100 \mathrm{~nm}$. E. Secretory stage. Calcium precipitates (arrows) appear in the subcuticular space (SCS) as the gland begins to secrete. C: cuticle; CW: cell wall; scale $=200 \mathrm{~nm}$. F. Secretory stage. Calcium precipitates (arrows) occur on the plasma membrane, cell wall (CW), and are 


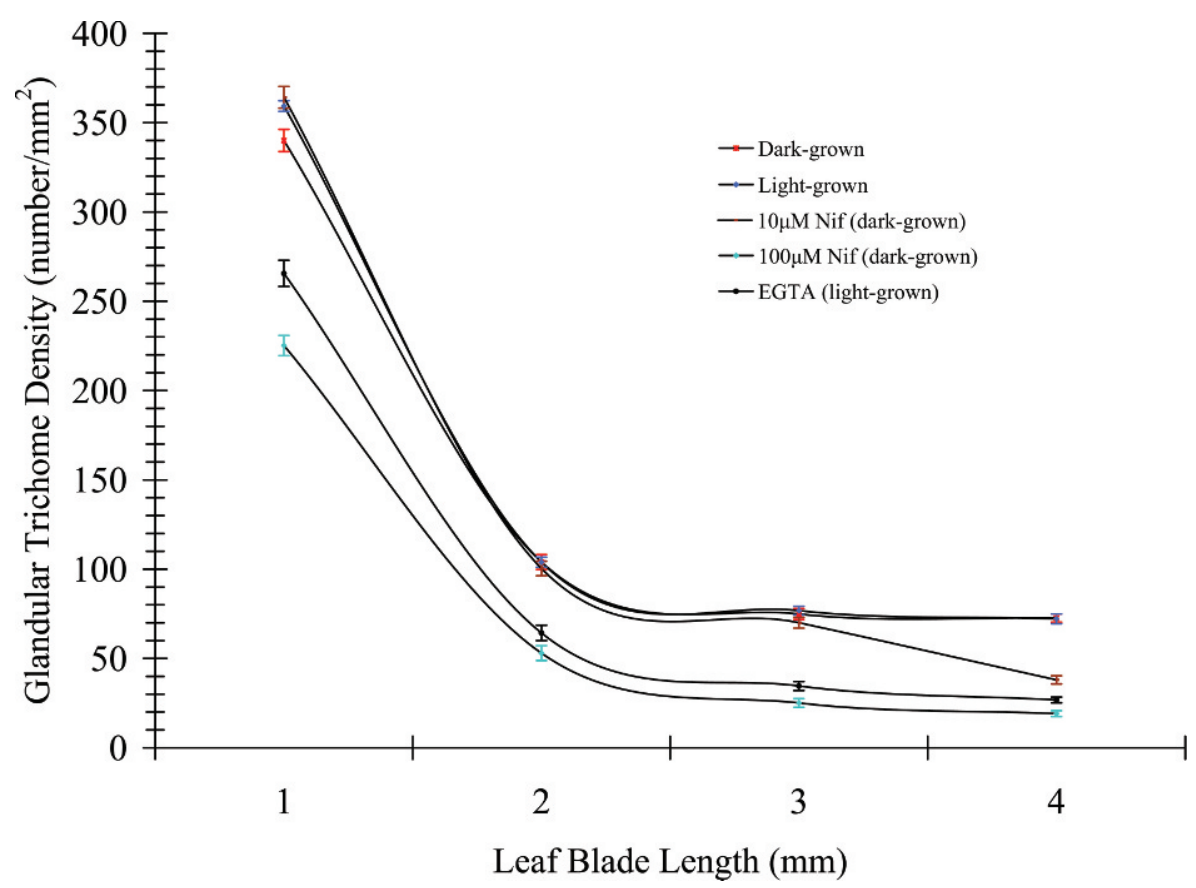

FIG. 3. Mean gland density (mean $\pm \mathrm{SE}$ ) on the abaxial sides of leaves grown under different treatments (light-grown control, dark-grown control, $10 \mu \mathrm{M}$ Nif, $100 \mu \mathrm{M}$ Nif, and EGTA).

completely disappears from the stalk and basal cells. Finally, at the post-secretory stage, the calcium disappears from the SCS, is irregularly distributed in the cytoplasm of the apical cells, and is common on the periphery of the organelles of these cells. This pattern suggests a role for calcium in gland development, secretion, and programmed cell death. The results of the experiments with the calcium channel blocker Nif and the calcium chelator EGTA support these conclusions.

Most of the $\mathrm{Ca}^{2+}$ absorbed by plants is found in the cell wall and vacuole (Gilroy et al. 1993, Tian and Russell 1997, Tian et al. 1998). Although the nature of the interaction between $\mathrm{Ca}^{2+}$ and the cell wall is poorly understood, a role for $\mathrm{Ca}^{2+}$ in strengthening the wall by cross-linking the carboxyl groups of the pectic polymers has been proposed (Cleland et al. 1990). In agreement with these findings, we found that both Nif and EGTA treatments lead to a loosening of the fibrillar structure of the cell wall.

The Role of Calcium in Secretion. A good deal of research has been done on trichome structure in relation to the secretory process in order to elucidate the secretory mechanism (Bosabalidis and Tsekos 1982, Bourett et al. 1994, Figueiredo and Pais 1994, Ascensão et al. 1997, Gersbach 2002). This research has shown that both the plastids (Wooding and Northcote 1965, Akers et al. 1978), and the endoplasmic reticulum (ER) (Schnepf 1972, Bourett et al. 1994, Ascensão et al. 1997, Turner et al. 2000) participate in the production of the essential oil.

Exocytosis has been suggested as the mechanism for transport of the protein-polysaccharide component of the essential oil from the cell to the subcuticular space in secretory trichomes (Ascensão and Pais 1998). The Apical cells at the secretory stage. Many calcium precipitates (arrowheads) on the plasma membrane and cell wall $(\mathrm{CW})$, but few in the vacuoles (V) and cytoplasm. P: plastid; scale $=500 \mathrm{~nm}$. H. Two apical cells at the post-secretory stage. Calcium precipitates (arrowheads) reappear in the cytoplasm and coat the degenerating mitochondria (M) and plastids (P), while they are absent from the subcuticular space (SCS). Scale $=200 \mathrm{~nm}$. 
Table 2. Calcium distribution at the secretory stage of light and dark-grown peltate glandular trichomes. mean $\pm \mathrm{SE}$

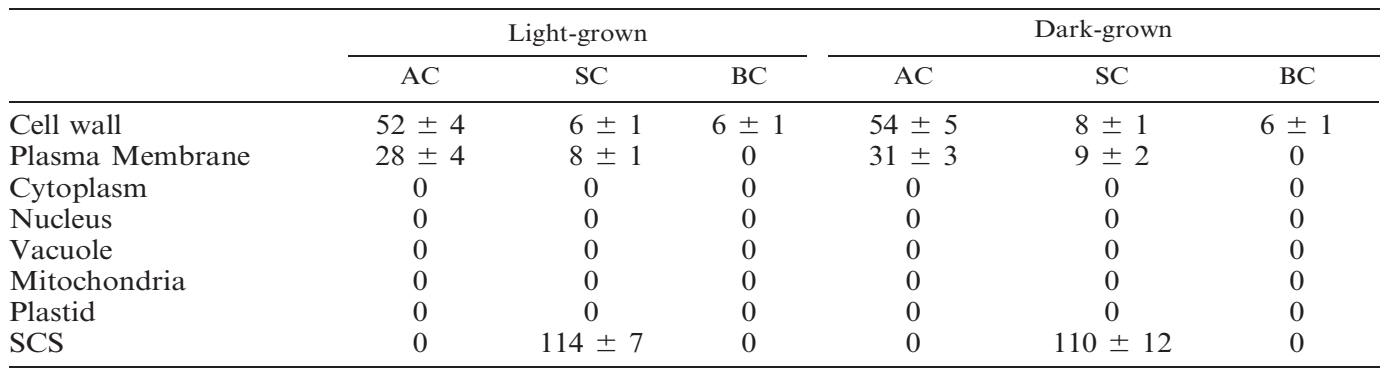

terpenoid component may be secreted directly from the plastids through the plasma membrane (Kim and Mahlberg 2003, Turner and Croteau 2004).

At the secretory stage in untreated plants, the greatest number of calcium precipitates appear in the SCS adjacent to the cell walls. Free calcium presumably travels through the stalk and basal cells to the apical cells via the plasmodesmata (Robards and Lucas 1990) until it reaches the SCS and adjacent cell walls. This distribution suggests that calcium mediates the secretory process. Over two decades ago Hepler and Wayne (1985) hypothesized that cytosolic free calcium was an obligate intracellular messenger coordinating cellular responses to numerous developmental cues. The hypothesis that each developmental cue or environmental challenge produces a unique $\left[\mathrm{Ca}^{2+}\right]_{\mathrm{c}}$ signature, which elicits specific cellular responses, was tested and supported by Knight et al. (1991), and Allen et al. (1999). It seems possible that the appearance of calcium precipitates in the SCS beside the cell wall is indicative of such a signature for secretion.

The fact that the amount of secretion was reduced by both Nif and EGTA suggests that calcium plays a role in stimulating secretion in Lavandula pinnata. That we found the same result with both calcium antagonists strengthens this conclusion. Nifedipine regulates plasma membrane $\mathrm{Ca}^{2+}$ channels in excitable cells, and can inhibit $\mathrm{Ca}^{2+}$ release from intracellular stores (Rosales and Brown 1992), while EGTA is a calcium chelator that binds intercellular calcium (Williams 1970). The reduction of secretion by two compounds that act in different ways suggests that the effect is due to the interference of these compounds with calcium metabolism, and is not a toxic effect of the chemicals.
The occurrence of multivesicular bodies near the plasma membrane of treated cells, suggests that the reduction in secretory product may be due to a disruption of exocytosis. Huang et al. (2008) describe the exocytosis of lipophilic vesicles into the periplasmic space during essential oil secretion of Lavandula pinnata. The presence of the multivesicular bodies reported here suggests that Nif and EGTA may interfere with this secretion process by interfering with exocytosis. However there is only one other (rather weak) report of lipophilic (essential oil?) secretion occurring by exocytosis (Gersbach 2002), and multivesicular bodies have also been identified as prevacuolar compartments, not secretory vesicles, in tobacco (Tse et al. 2004). These facts weaken the supposition that the multivesicular bodies may be abnormal secretory vesicles. Moreover, recycling of membrane materials through endocytosis has been suggested as a stress response that is protective against cell death (Levine 2002), and multivesicular bodies have been shown to be one way in which this recycling takes place (An et al. 2006). In support of the hypothesis that the multivesicular bodies are abnormal secretory vessels is the fact that those reported here appear to be aggregates of closely appressed vesicles rather than a system of small vesicles enclosed in a single larger one (Levine 2002, Tse et al. 2004, An et al. 2006), and the fact that An et al. (2006) could not rule out the possibility that some multivesicular bodies are secretory.

The role of $\mathrm{Ca}^{2+}$ in carbohydrate exocytosis has been studied in several systems. A high tipfocused $\left[\mathrm{Ca}^{2+}\right]$ gradient in pollen tubes and root hairs has been shown to play a role in exocytosis (Malhó and Trewavas 1996, Wymer et al. 1997, Campanoni and Blatt 2007). 

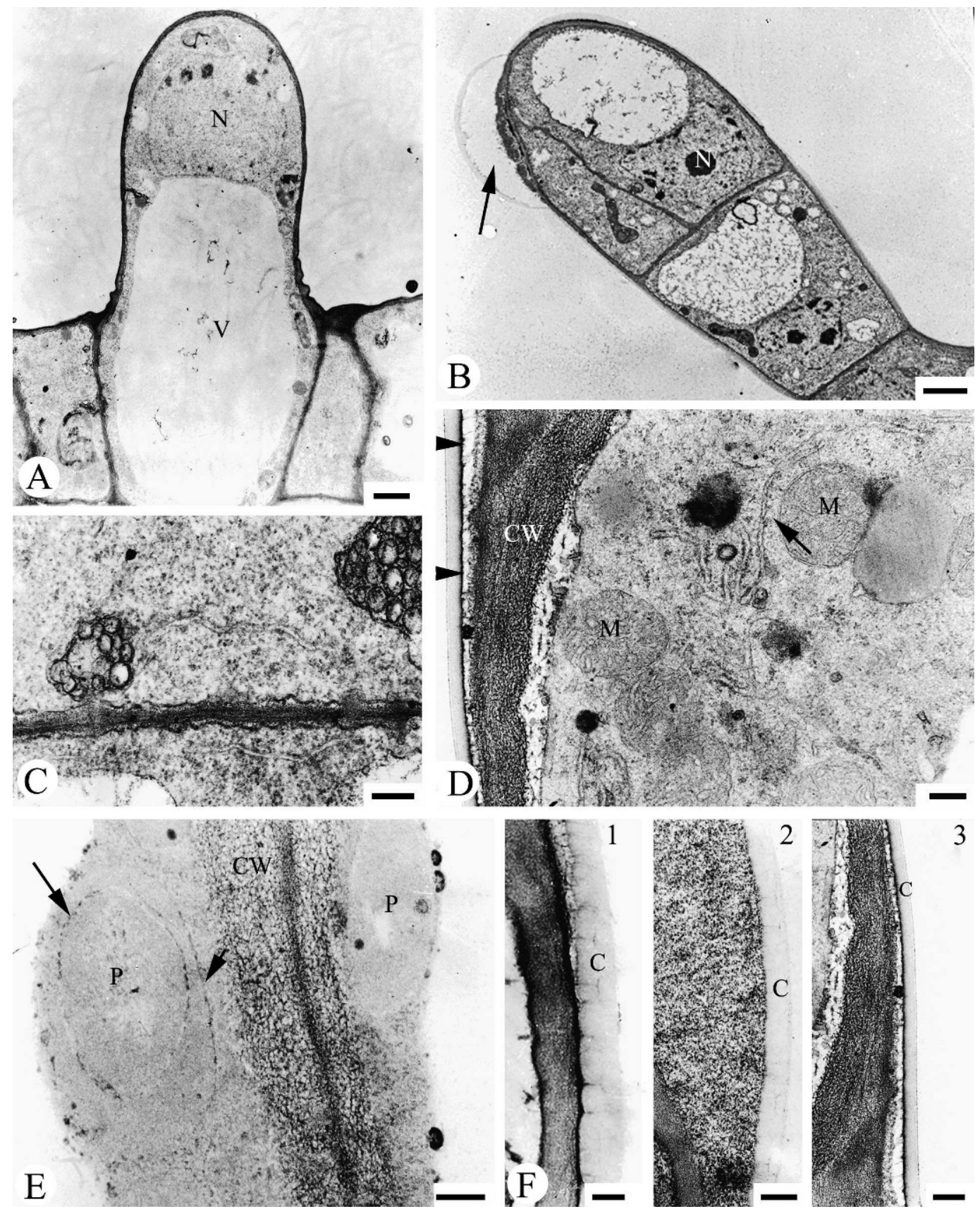

FIG. 4. TEM micrographs of calcium distribution in peltate glandular trichomes treated with $100 \mu \mathrm{M}$ Nif. A. Early presecretory stage. The initial cell of a glandular trichome with few organelles, decreased cytoplasmic density, and no calcium precipitates. N: nucleus; V: vacuole; scale $=1 \mu \mathrm{m}$. B. Early presecretory, three-celled stage. Abnormal separation of the cuticular layer from the cell wall to form an abnormal subcuticular space (SCS, arrow). Scale $=2 \mu \mathrm{m}$. C. Apical cells at the secretory stage. Anomalous compound vesicles in the vicinity of the plasma membrane. Scale $=200 \mathrm{~nm}$. D. Apical cell at the secretory stage. Little secretory product occurs in the subcuticular space (SCS, arrowheads), and many mitochondria (M) appear near the plasma membrane. The RER (arrow) has a few ribosomes. CW: cell wall; scale $=200 \mathrm{~nm}$. E. Post-secretory stage, apical cells. Calcium precipitates (arrows) occur on the outer membrane of the disorganized plastids (P), while the cell wall $(\mathrm{CW})$ has a lax fibrillar appearance. Scale $=200 \mathrm{~nm}$. F. Comparison of the cuticular layer under three treatments 1) light-grown control, 2) dark-grown control, and 3) $100 \mu \mathrm{M}$ Nif. C: cuticle; scales $=100 \mathrm{~nm}$. 
$\mathrm{Ca}^{2+}$ is also involved in the regulation of vesicle fusion in pollen tubes (Hepler et al. 1994, Pierson et al. 1996, Carol et al. 1997, Monteiro et al. 2005). Lin and Yang (1997) speculated that Rop GTPases might mediate a $\mathrm{Ca}^{2+}$-dependent pathway that leads to exocytosis. They suggested that Rop GTPases may carry out this function by regulating the activity of $\mathrm{Ca}^{2+}$-dependent annexins. More recently, it was found that increases in GTP levels can promote exocytosis (and growth), but do not significantly affect $\left[\mathrm{Ca}^{2+}\right]_{\mathrm{c}}$ distribution (Camaco and Malhó 2003). This finding suggests that exocytosis is regulated both by a $\left[\mathrm{Ca}^{2+}\right]_{\mathrm{c}}$ gradient and the activity of GTPases. Rop GTPases are likely candidates for the mediation of $\mathrm{Ca}^{2+} / \mathrm{GTP}$ crosstalk as shown by knock-out experiments in growing pollen tubes (Camaco and Malhó 2003).

Additional support for a role for calcium in Lavandula pinnata secretion, and possibly in exocytosis, comes from TEM observations that reveal that the location of calcium precipitates in the SCS of L. pinnata is similar to calcium distribution in actively growing pollen tubes (Xie et al. 2005a).

Cuticle Formation. In addition to a reduction in secretory product, treatment with either Nif or EGTA leads to a lax cell wall, and a thin cuticle. The thin cuticle indicates that the transportation path of the cuticular material has been disturbed. Since this pathway likely involves the direct secretion of cuticular material through the plasma membrane to the apoplast (Mahlberg and Kim 1991, Kim and Mahlberg 1995, Samuels et al. 2008), we can deduce a relationship between calcium and these processes (Roy et al. 1999). It is possible that calcium regulates the function of CER5 and/or WBC11, two ATP binding cassette transporters that have been implicated in wax export (Pighin et al. 2004, Bird et al. 2007, Samuels et al. 2008).

It has been suggested that during secretion cuticle-wall separation occurs at a predetermined zone of weakness (Bourett et al. 1994, Ascensão et al. 1997). In Lavandula pinnata both Nif and EGTA treatments lead to an abnormal cuticle-wall separation, and early SCS formation. It is possible that the changes in calcium metabolism caused by these treatments weaken the junction between the cuticle and the wall, which induces early cuticle-wall separation.
Programmed Cell Death. Calcium is an important molecule in signaling programmed cell death (Berridge et al. 1998, Santelia and Carafou 1997, Snedden and Fromm 2001, Medvedev 2005, Ma and Berkowitz 2007), and may play a role in the necrosis of the trichomes. Its role in programmed cell death has led some authors to suggest that certain patterns of calcium distribution may be associated with cell death. For instance, in a study of microsporogenesis in male sterile Chinese cabbage, Xie et al. (2005b) suggested that the high occurrence of calcium precipitates in the tapetum at the binucleate stage signals the beginning of programmed cell death. The appearance of calcium precipitates on the organelle membranes during the postsecretory stage may also be associated with programmed cell death.

Conclusions. Essential oil secretion in $\mathrm{La}$ vandula pinnata is calcium dependent. Changes in calcium distribution during development suggest that calcium also has a role in gland development, and programmed cell death. Removal of calcium with Nif or EGTA results in a reduction in gland density on the abaxial surface of leaves, cells with decreased cytoplasmic density early in development, formation of a lax and fibrillar cell wall, abnormal formation of the subcuticular space, thinning of the cuticle, reduced secretion, and the presence of multivesicular bodies near the plasma membrane. The concentration of calcium in the subcuticular space and adjacent cell wall during the secretory process may be a signature for secretion.

\section{Literature Cited}

Akers, C. P., J. A. Weybrew, and R. C. Long. 1978. Ultrastructure of glandular trichomes of leaves of Nicotiana tabacum L. Am. J. Bot. 65: 282-292.

Allen, G. J. And D. SAnders. 1997. Vacuolar ion channels of higher plants. Adv. Bot. Res. 25: 217-252.

Allen, G. J., J. M. Kwak, S. P. Chu, J. Liopis, R. Y. Tsien, J. F. Harper, and J. I. SChroeder. 1999. Cameleon calcium indicator reports cytoplasmic calcium dynamics in Arabidopsis guard cells. Plant J. 19: 735-747.

An, Q., R. Huckelhoven, K.-H. Kogel, and A. J. E. van BEL. 2006. Multivesicular bodies participate in a cell wall-associated defense response in barley leaves attacked by the pathogenic powdery mildew fungus. Cell. Microbio. 8: 1009-1019. 
Ascensão, L. And M. S. PAis. 1998. The leaf capitate trichomes of Leonotis leonurus: Histochemistry, ultrastructure and secretion. Ann. Bot. 81: 263-271.

Ascensão, L., N. Marques, and M. S. Pais. 1997. Peltate glandular trichomes of Leonotis leonurus leaves: Ultrastructure and histochemical characterization of secretions. Int. J. Plant Sci. 158: 249-258.

Berridge, M. J., M. D. Bootman, And P. Lipp. 1998. Calcium-a life and death signal. Nature 395: 645-648.

Bird, D., F. Beisson, A. Brigham, J. Shin, S. Greer, R. Jetter, L. Kunst, X-W. Wu, A. Yephremov, and L. SAMuels. 2007. Characterization of Arabidopsis ABCG11WBC/11, an ATP binding cassette (ABC) transporter that is required for cuticular lipid secretion. Plant $\mathbf{J}$. 52: 485-498.

Bosabalidis, A. M. And L. Tsekos. 1982. Glandular scale development and essential oil secretion in Origanum dictamnus L. Planta 156: 496-504.

Bourett, T. M., R. J. Howard, D. P. O'Keefe, and D. L. Hallahan. 1994. Gland development on leaf surfaces of Nepeta racemosa. Int. J. Plant Sci. 155: 623-632.

Bush, D. S. 1995. Calcium regulation in plant cells and its role in signaling. Ann. Rev. Plant Physiol. 46: 95-122.

Camaco, L. and R. Malhó. 2003. Endo/exocytosis in the pollen tube apex is differentially regulated by $\mathrm{Ca}^{2+}$ and GTPases. J. Exp. Bot. 54: 83-92.

Campanoni, P. and M. R. Blatt. 2007. Membrane trafficking and polar growth in root hairs and pollen tubes. J. Exp. Bot. 58: 65-74.

Chen, S-H., J-P. Liao, M-Z. Luo, and B. K. Kirchoff. 2008. Calcium distribution and function during anther development of Torenia fournieri L. Ann. Bot. Fennici 45: 195-203.

Clark, L. J., J. G. C. Hamilton, J. V. Chapman, M. J. C. Rhodes, and D. L. Hallanhan. 1997. Analysis of monoterpenoids in glandular trichomes of catmint Nepeta racemosa. Plant J. 11: 1387-1393.

Cleland, R. E., S. S. Virk, D. Taylor, and T. B. JORKMAN. 1990. Calcium, cell walls and growth, p. 9-16. In R. T. Leonard and P. K. Hepler [eds.], Calcium in plant growth and development. American Society of Plant Physiologists, Rockville, MD.

Dentinger, P. J. 2003. Stability of nifedipine in an extemporaneously compounded oral solution. Am. J. Health-Syst. Ph. 60: 1019-1022.

ECKARDT, N. A. 2001. A calcium-regulated gatekeeper in phloem sieve tubes. Plant Cell 13: 989-992.

Epstein, E. 1972. Mineral Nutrition of Plants: Principles and Perspectives. Wiley, New York, NY. 412 p.

FAN, L-M., H-Y. YANG, AND C. ZHOU. 1996. Effects of nifedipine on pollen germination, pollen tube growth and division of generative nucleus in Nicotiana tabacum. Acta. Bot. Sin. 38: 686-691. (in Chinese).

Figueiredo, A. C. And M. S. Pais. 1994. Ultrastructural aspects of the glandular cells from the secretory trichomes and from the cell suspension cultures of Achillea millefolium ssp. millefolium. Ann. Bot. 74: 179-190.

Franklin-Tong, V. E. 1999. Signaling and modulation of pollen tube growth. Plant Cell 11: 727-738.

Gersbach, P. V. 2002. The essential oil secretory structures of Prostanthera ovalifolia (Lamiaceae). Ann. Bot. 89: 255-260.

Ge, L-L., H-Q. Tian, and S. D. Russell. 2007. Calcium function and distribution during fertilization in angiosperms. Am. J. Bot. 94: 1046-1060.

Gilroy, S., P. C. Bethke, and R. L. Jones. 1993. Calcium homeostasis in plants. J. Cell Sci. 106: 453-462.

Górska-Brylass, A., R. Butowt, And M. L. Rodriguez-GARCIA. 1997. Distribution of loosely-bound calcium in the vegetative and generative cells of the pollen grains in Chlorophytum elatum. Biol. Plantarum 40: 169-181.

Hepler, P. K., D. D. Miller, E. S. Pierson, and D. A. Callaham. 1994. Calcium and pollen tube growth, p. 111-123. In A. G. Stephenson and T-H. Kao [eds.], Pollen-pistil interactions and pollen tube growth. American Society of Plant Physiologists, Rockville, MD.

Hepler, P. K. and R. O. Wayne. 1985. Calcium and plant development. Ann. Rev. Plant Physiol. 36: 397-439.

Herrmann, A. and H. H. Felle. 1995. Tip growth in root hair cells of Sinapis alba L.: Significance of internal and external $\mathrm{Ca}^{2+}$ and $\mathrm{pH}$. New Phytol. 129: 523-533.

Huang, S-S., J-P. Liao, and Q-G. Wu. 2005. Developmental anatomy of trichomes in Lavandula pinnata L. J. Tropic. Subtropic. Bot. 14: 134-140. (in Chinese).

Huang, S-S., B. K. Kirchoff, and J-P. Liao. 2008. The capitate and peltate glandular trichomes of Lavandula pinnata L. (Lamiaceae): Histochemistry, ultrastructure and secretion. J. Torrey Bot. Soc. 135: 155-167.

JiAn, L-C., J-H. Li, W-P. Chen, H. L. PAul, ANd G. A. Gilbert. 1999. Cytochemical localization of calcium and $\mathrm{Ca}^{2+}$-ATPase activity in plant cells under chilling stress: A comparative study between the chilling-sensitive maize and the chilling-insensitive winter wheat. Plant Cell Physiol. 40: 1061-1071.

Kim, E. S. And P. G. Mahlberg. 1995. Glandular cuticle formation in Cannabis (Cannabaceae). Am. J. Bot. 82: 1207-1214.

Kim, E. S. And P. G. Mahlberg. 2003. Secretory vesicle formation in the secretory cavity of glandular trichomes of Cannabis sativa L. (Cannabaceae). Mol. Cell. 15: 387-395.

Knight, M. R., A. K. Campbell, S. M. Smith, and A. J. Trewavas. 1991. Transgenic plant aequorin reports the effects of touch and cold-shock and elicitors on cytoplasmic calcium. Nature 352: 524-526.

Levine, A. 2002. Regulation of stress responses by intracellular vesicle trafficking? Plant Physiol. Biochem. 40: 531-535.

LIN, Y. AND Z. YANG. 1997. Inhibition of pollen tube elongation by microinjected anti-Rop1Ps antibodies suggests a crucial role for Rho-type 
GTPases in the control of tip growth. Plant Cell 14: S389-S400.

Ma, W. And G. A. Berkowitz. 2007. The grateful dead: Calcium and cell death in plant innate immunity. Cell. Microbiol. 9: 2571-2585.

Machado, S. R., E. A. Gregório, and E. GuimarÃES. 2006. Ovary peltate trichomes of Zeyheria montana (Bignoniaceae): Developmental ultrastructure and secretion in relation to function. Ann. Bot. 97: 357-369.

Mahlberg, P. G. And E. S. Kim. 1991. Cuticle development on glandular trichomes of Cannabis sativa (Cannabaceae). Am. J. Bot. 78: 1113-1122.

Malhó, R. and N. D. Trewavas. 1996. Localized apical increase of cytosolic free calcium control pollen tube orientation. Plant Cell 8: 1935-1949.

Mascarenhas, J. P. and M. Leonarad. 1962. Chemotropic response of Antirrhinum majus pollen to calcium. Nature 196: 292-293.

Medvedev, S. S. 2005. Calcium signaling system in plants. Rus. J. Plant Physiol. 52: 249-270.

Monteiro, D., Q. Liu, S. Lisboa, G. E. Scherer, H. Quader, AND R. Malhó. 2005. Phosphoinositides and phosphatidic acid regulate pollen tube growth and reorientation through modulation of $\left[\mathrm{Ca}^{2+}\right]_{\mathrm{c}}$ and membrane secretion. J. Exp. Bot. 56: 1665-1674.

Moysset, L. And E. Simón. 1990. Effect of EGTA on nyctinastic closure mediated by phytochrome in Albizia lophantha. Plant Cell Physiol. 31: 187-193.

Murashige, T. And F. Skoog. 1962. A revised medium for rapid growth and bioassay with tobacco tissue culture. Physiol. Plant 15: 473-497.

Picton, J. M. And M. W. Steer. 1985. The effects of ruthenium red, lanthanum, fluorescein isothiocyanate and trifluoperazine on vesicle transport, vesicle fusion and tip extension in pollen tubes. Planta 163: 20-26.

Pierson, E. S., D. D. Miller, D. A. Callaham, A. M. Shipley, B. A. Rivers, M. Cresti, and P. K. Hepler. 1994. Pollen tube growth is coupled to the extracellular calcium ion influx and the intracellular calcium gradient: Effect of BAPTA-type buffer and hypertonic media. Plant Cell 6: 1815-1828.

Pierson, E. S., D. D. Miller, D. A. Callaham, J. Van-Aken, G. Hackett, and P. K. Hepler. 1996. Tip-localized calcium entry fluctuates during pollen tube growth. Dev. Biol. 174: $160-173$.

Pighin, J. A., H-Q. Zheng, L. J. Balakshin, I. P. Goodman, T. L. Western, R. Jetter, L. Kunst, AND A. L. SAmuels. 2004. Plant cuticular lipid export requires an ABC transporter. Science 306: 702-704.

Plieth, C. 2001. Plant calcium signaling and monitoring: Pros and cons and recent experimental approaches. Protoplasma 218: 1-23.

Reiss, H. D. AND W. Herth. 1985. Nifedipinesensitive calcium channels are involved in polar growth of lily pollen tubes. J. Cell Sci. 76: 247-254.

Robards, A. W. And W. J. Lucas. 1990. Plasmodesmata. Ann. Rev. Plant Physiol. Plant Mol. Biol. 41: 369-419.
Rosales, C. And E. J. Brown. 1992. Calciumchannel blockers nifedipine and diltiazem inhibit $\mathrm{Ca}^{2+}$ release from intracellular stores in neutrophils. J. Biol. Chem. 267: 1443-1448.

Roy, S., T. L. Holdaway-Clarke, G. R. Hackett, J. G. Kunkel, E. M. Lord, And P. K. Hepler. 1999. Uncoupling secretion and tip growth in lily pollen tubes: Evidence for the role of calcium in exocytosis. Plant J. 19: 379-386.

Sajo, M. G., C. A. Furness, C. J. Prychid, and P. J. RudALl. 2005. Microsporogenesis and anther development in Bromeliaceae. Grana 44: 65-74.

SAKAI-WADA, A. AND S. YAGI. 1993. Ultrastructural studies on the $\mathrm{Ca}^{2+}$ localization in the dividing cells of the maize root tip. Cell Struct. Funct. 18: 389-397.

Samuels, L., L. Kunst, and R. Jetter. 2008. Sealing plant surfaces: Cuticular wax formation by epidermal cells. Ann. Rev. Plant Bio. 59: 683-707.

Sanders, D., C. Brownlee, and J. F. Harper. 1999. Communicating with calcium. Plant Cell 11: 691-706.

Santelia, L. And E. Carafou. 1997. Calcium signaling in the cell nucleus. The FASEB J. 11: 1091-1109.

Schnepf, E. 1972. Tubuläres endoplasmatisches reticulum in drüsen mit lipophilen ausscheidungen von Ficus, Ledum, und Salvia. Biochem. Physiol. Pflanz. 163: 113-125.

Scrase-Field, S. A. And M. R. Knight. 2003. Calcium: Just a chemical switch? Curr. Opin. Plant Biol. 6: 500-506.

Slocum, R. D. And S. J. Roux. 1982. An improved method for the subcellular localization of calcium using a modification of the antimonate precipitates technique. J. Histochem. Cytochem. 617-629.

Snedden, W. A. And H. Fromm. 2001. Calmodulin as a versatile calciumn signal transducer in plants. New Phytol. 151: 35-66.

Suzuki, K., M. Shono, And Y. Egawa. 2003. Localization of calcium in the pericarp cells of tomato fruits during the development of blossom-end rot. Protoplasma 222: 149-156.

TAKagi, S. AND R. Nagai. 1983. Regulation of cytoplasmic streaming in Vallisneria mesophyll cells. J. Cell Sci. 62: 385-405.

Taylor, L. P. and G. F. Hepler. 1997. Pollen germination and tube growth. Ann. Rev. Plant Physiol. Plant Mol. Biol. 48: 461-191.

Tian, H-Q., A. Kuang, M. E. Musgrave, and S. D. Russell. 1998. Calcium distribution in fertile and sterile anthers of a photoperiod-sensitive genic male-sterile rice. Planta 204: 183-192.

Tian, H-Q., H. Zhu, and S. D. Russell. 2000. Calcium changes in ovules and embryo sacs of Plumbago zeylanica L. Sex. Plant Rep. 13: 11-20.

Tian, H-Q. AND S. D. Russell. 1997. Calcium distribution in fertilized and unfertilized ovules and embryo sacs of Nicotiana tabacum L. Planta 202: 93-105.

Trewavas, A. And R. Malhó. 1998. $\mathrm{Ca}^{2+}$ signaling in plant cells: The big network! Curr. Opin. Plant Biol. 1: 428-433.

Tse, Y-C., B-X. Mo, S. Hillmer, M. Zhao, S-W. Lo, D. G. Robinson, AND L-W. JiAng. 2004. 
Identification of multivesicular bodies as prevacuolar compartments in Nicotiana tabacum BY-2 cells. Plant Cell 16: 672-693.

Turner, G. W., J. Gershenzon, and R. B. Croteau. 2000. Development of peltate glandular trichomes of Peppermint. Plant Physiol. 124: 665-679.

Turner, G. W. and R. B. Croteau. 2004. Organization of monoterpene biosynthesis in Mentha. Immunocytochemical localizations of geranyl diphosphate synthase, limonene-6-hydroxylase, isopiperitenol dehydrogenase, and pulegone reductase. Plant Physiol. 136: 4215-4227.

Vaughan, M. A., T. J. Mulkey, and C. W. Goff. 1987. Localization of calcium in roots and microsomal membranes of corn by direct pyroantimonate precipitation. J. Histochem. Cytochem. 35: 781-788.

Weisenseel, M. H. and L. F. JAFFe. 1976. The major growth current through lily pollen tubes enters as $\mathrm{K}^{+}$and leaves as $\mathrm{H}^{+}$. Planta 133: 1-7.

Werker, E. 1993. Function of essential oil-secreting glandular hairs in aromatic plants of the Lamiaceae. Flavor Fragr. J. 8: 249-255.

Wheeler, G. L. And C. BRownlee. 2008. $\mathrm{Ca}^{2+}$ signaling in plants and green algae-changing channels. Trends Plant Sci. 13: 506-514.

Wick, S. M. AND P. K. Hepler. 1982. Selective localization of intracellular $\mathrm{Ca}^{2+}$ with potassium antimonate. J. Histochem. Cytochem. 30: 11901204
Williams, R. J. P. 1970. The biochemistry of sodium, potassium, magnesium, and calcium. Q. Rev. Chem. Soc., London 24: 331-365.

Wooding, F. B. P. And D. H. Northcote. 1965. The fine structure of the mature resin canal cells of Pinus pinea. J. Ultra. Res. 3: 233-244.

Wymer, C. L., T. N. Bibikova, and S. Gilroy. 1997. Cytoplasmic free calcium distributions during the development of root hairs of Arabidopsis thaliana. Plant J. 12: 427-439.

Xie, C-T., Y-L. Qiu, L. Ge, S-C. Chen, And H-Q. TIAn. 2005a. The distribution of calcium in the stigma and style of tobacco during pollen germination and tube growth. J. Plant Physiol. Mol. Biol. 31: 53-61. (in Chinese).

Xie, C-T., Y-H. Yang, Y-L. Qiu, L-L. Ge, And H-Q. TIAN. 2005b. Calcium distribution in fertile and sterile anthers of a genic male sterile Chinese cabbage. J. Plant Physiol. Mol. Biol. 31: 615-624. (in Chinese).

Zhang, G. And D. D. CAss. 1997. Calcium signaling in sexual reproduction of flowering plants. Recent Res. Plant Physiol. 1: 75-83.

ZhANG, Z-S., R-Q. LI, AND J-B. WANG. 2000. Effects of $\mathrm{Ca}^{2+}, \mathrm{La}^{3+}$ and EGTA treatments on the responses of pepper leaves to heat stress. J. Wuhan Univ. 46: 253-256. (in Chinese).

Zhao, J., H-Y. YANG, AND E. M. Lord. 2004. Calcium levels increase in the lily stylar transmitting tract after pollination. Sex. Plant Rep. 16: 259-263. 